Mithilfe einer prospektiven Studie wurde bei normalgewichtigen Frauen mit ungünstig proportionierten Fettdepots (Bauch, Hüften, Oberschenkel) nach einer Fettabsaugung untersucht, welche anatomischen Muster der Fett-Wiedereinlagerung es möglicherweise gibt. $\mathrm{Zu}$ Beginn der Studie erfolgten Untersuchungen des Körperaufbaus: DXA-Methode (primärer Endpunkt), Messungen des Umfangs von Bauch und Gliedmaßen, der subkutanen Hautfaltendicke sowie MRT von Rumpf und Gliedmaßen. Anschließend wurden die 32 Teilnehmerinnen im Alter von 36 +/- 1 Jahren nach dem $\mathrm{Zu}$ fallsprinzip unterteilt: eine Gruppe erhielt eine geringvolumige Fettabsaugung ( $\mathrm{n}=14)$, eine war Kontrollgrup- pe $(n=18)$. Die Frauen in der Absaugungsgruppe wurden innerhalb von vier Wochen operiert. Nach jeweils sechs Wochen, sechs Monaten und einem Jahr wurden die Untersuchungen wie zu Beginn der Studie wiederholt. Die Frauen hatten sich verpflichtet, im Beobachtungszeitraum keine Lifestyle-Veränderungen vorzunehmen.

Ergebnisse: Die Frauen scheinen von einer geringvolumigen Fettabsaugung langfristig nicht wirklich $\mathrm{zu}$ profitieren. Der Körperfettanteil war nach einem Jahr nicht mehr signifikant niedriger als bei der Kontrollgruppe. Das neu aufgebaute Körperfett war statt an den Oberschenkeln in der Bauchregion abgelagert.

\section{Verkürzte Leukozyten-Telomere Dicke Kinder altern vor}

Fettleibige Kinder haben signifikant kürzere Leukozyten-Telomere als normalgewichtige Gleichaltrige. Die Länge der Leukozyten-Telomere gilt als Marker des biologischen Alters, der auch mit altersunabhängigen Zuständen wie Herz-Kreislauf-Erkrankungen und Diabetes-Typ-2 in Verbindung gebracht wird. Das zeigt eine französische Studie mit 793 Kindern im Alter von 2 bis 17 Jahren. Bei den Kindern (471 waren bereits in früher Kindheit fettleibig und 322 galten als normalgewichtige Kontrollgruppe) wurde die LTL mit quantita- tiver Multiplex-RT-PCR gemessen. Die mittlere LTL der 2 Gruppen wurde verglichen, wobei auch das Verhältnis zwischen Telomerlänge und bestimmten anthropometrischen wie biochemischen Faktoren untersucht wurde.

Ergebnisse: Die mittlere LTL fettleibiger Kinder war um 23,9\% kürzer als die schlanker Kinder $(\mathrm{p}<0,0001)$. Es gab eine inverse Assoziation zwischen der Telomerlänge und dem Alter, dem Logarithmus des Gewichts und der Größe in der Kontroll- und der Fallgruppe.

\title{
Ungesunder Alkoholkonsum
}

\section{Rauschtrinken erhöht das Risiko für Herzerkrankungen}

\begin{abstract}
Wie wirkt sich Alkoholkonsum auf die Entstehung von Herzinfarkt, schwere Koronarereignisse mit Todesfolge und A. pectoris aus? Dazu wurden in eine Studie 2405 herzgesunde Männer aus Belfast und 7373 aus drei Zentren in Frankreich aufgenommen. Es wurde festgehalten: Alkoholkonsum, Häufigkeit des Rauschtrinkens (d.h. $>50 \mathrm{~g}$ Alkohol an mind. 1 Tag/Woche), regelmäßiger Alkoholkonsum (mind. 1 Tag/Woche und $<50$ g Alkohol einmalig), die Menge und Häufigkeit des Konsums und die Getränkeart. Alle Koronarereignisse in der 10-jährigen Beobachtung wurden prospektiv registriert.
\end{abstract}

Ergebnisse: Der Alkoholkonsum lag im Schnitt bei 22,1 $\mathrm{g} / \mathrm{d}$ in Belfast und bei 32,8 g/d in Frankreich. In Belfast waren 9,4\% der Männer, in Frankreich 0,5\% Rauschtrinker. 683 (7\%) entwickelten in der 10-jährigen Beobachtungszeit ischämische Herzkrankheiten, 322 (3,3\%) schwere Koronarereignisen, 361 (3,7\%) A. pectoris. Risikoquotient für schwere Koronarereignisse in Belfast versus Frankreich vor der Adjustierung auf KonsumMuster und Weinkonsum: 1,76 (95\%-KI 1,37-2,67), danach: 1,09 (95\%-KI 0,79-1,50). Nur der Weinkonsumwar mit einem geringeren Risiko für schwere Koronarereignisse assoziiert. Regelmäßiger moderater Alkoholkonsum, wie in Frankreich üblich, erhöht das Risiko nur gering, Rauschtrinker, wie in Irland oft anzutreffen, haben ein höherer Risiko für schwere Koronarereignisse. Quelle (3 Texte): www.lifestyle-telegramm.de
Hernandez TL, Kittelson JM, Law CK et L. Obesity (Silver Spring) 2011;19(7):1388-95.

Buxton JL, Walters RG, Visvikis-Siest $S$ et al. J Clin Endocrinol Metab 2011; 96(5):1500-5.

Ruidavets JB, Ducimetière $P$, Evans A.et al. BMJ. 2010 Nov 23;341:c6077. doi: 10.1136/bmj.c6077.

Das Lifestyle-Telegramm zu hochwertigen Publikationen mit dem Thema "Lebensstil" kann als Newsletter kostenlos abonniert werden und erscheint monatlich per Mail. Viele weitere entsprechende Kurzreferate gibt's unter: www.lifestyle-telegramm.de 